Scientific Paper

\title{
The effective and water-equivalent diameters as geometrical size functions for estimating CT dose in the thoracic, abdominal, and pelvic regions
}

\author{
Winda Kusuma DeWI ${ }^{1}$, Choirul ANAM ${ }^{1}$, Eko HIDAYANTO ${ }^{1}$, Arrum NITASARI ${ }^{1}$, Geoff DougherTY ${ }^{2}$ \\ ${ }^{1}$ Department of Physics, Faculty of Sciences and Mathematics, Diponegoro University, Jl. Prof. Soedarto SH, Tembalang, \\ Semarang 50275, Central Java, Indonesia. \\ ${ }^{2}$ Department of Applied Physics and Medical Imaging, California State University Channel Islands, Camarillo, CA 93012, \\ USA \\ *E-mail address: anam@fisika.fsm.undip.ac.id
}

\begin{abstract}
Purpose: The aim of this work was to establish the relationships of patient size in terms of effective diameter ( $\left.\mathrm{D}_{\text {eff }}\right)$ and water-equivalent diameter $\left(\mathrm{D}_{\mathrm{w}}\right)$ with lateral (LAT) and anterior-posterior (AP) dimensions in order to predict the specific patient dose for thoracic, abdominal, and pelvic computed tomography (CT) examinations.

Methods: A total of 47 thoracic images, 79 abdominal images, and 50 pelvic images were analyzed in this study. The patient's images were retrospectively collected from Dr. Kariadi and Kensaras Hospitals, Semarang, Indonesia. The slices measured were taken from the middle of the scan range. The calculations of patient sizes (LAT, AP, $D_{\text {eff, }}$, and $\mathrm{D}_{\mathrm{w}}$ ) were automatically performed by IndoseCT $20 \mathrm{~b}$ software. $\mathrm{D}_{\text {eff }}$ and $\mathrm{D}_{\mathrm{w}}$ were plotted as functions of LAT, AP, and AP+LAT. In addition, $\mathrm{D}_{\mathrm{w}}$ was plotted as a function of $\mathrm{D}_{\text {eff. }}$.

Results: Strong correlations of $\mathrm{D}_{\text {eff }}$ and $\mathrm{D}_{\mathrm{w}}$ with LAT, AP, and AP+LAT were found. Stronger correlations were found in the $D_{\text {eff }}$ curves $\left(R^{2}>0.9\right)$ than in the $D_{w}$ curves $\left(R^{2}>0.8\right)$. It was found that the average $D_{\text {eff }}$ was higher than the average $\mathrm{D}_{\mathrm{w}}$ in the thoracic region, the average values were similar in the abdominal and pelvic regions.

Conclusion: The current study extended the study of the relationships between $\mathrm{D}_{\text {eff }}$ and $\mathrm{D}_{\mathrm{w}}$ and the basic geometric diameter LAT, AP, and AP+LAT beyond those previously reported by AAPM. We evaluated the relationships for three regions, i.e. thoracic, abdominal, and pelvic regions. Based on our findings, it was possible to estimate $D_{\text {eff }}$ and $D_{w}$ from only the LAT or AP dimension.
\end{abstract}

Key words: anterior-posterior dimension; lateral dimension; effective diameter; water-equivalent diameter; computed tomography.

\section{Introduction}

The capability of computed tomography (CT) to produce highquality images has steadily grown since its introduction in the 1970s. Improvements in CT hardware has led to a new generation of multidetector-row CT (MDCT) with greater X-ray tube power, faster acquisition time, and dual-energy and even multi-energy x-rays capabilities. ${ }^{1,2}$ Currently, one axial image can be acquired in 0.005 seconds, whereas it took about 300 seconds to acquire one axial image in a first-generation scanner. ${ }^{3}$ Advances in software have led to iterative reconstruction (IR) techniques and tube current modulation (TCM) allowing low dose CT. ${ }^{2,4}$ These improvements have made CT a reliable and desirable imaging modality. In cardio-thoracic imaging, for example, MDCT has become a viable non-invasive option due to its ability to accurately evaluate coronary artery abnormalities. $^{5}$
An annual statistical study by National Health Service (NHS), England, reported that 5,959,860 examinations used CT scanners in $2019 / 2020 .^{6}$ This number has increased by $5.2 \%$ compared to the previous year and it was predicted that it will continue to increase for the next few years. This trend of increasing use of $\mathrm{CT}$ also occurred in North America, Asia, and Italy. ${ }^{7,8}$ As a consequence these populations will receive high $\mathrm{x}$ ray doses. ${ }^{9}$

There have been several indicators used to quantify dose radiation of CT scanners, such as multiple scan average dose (MSAD), computed tomography dose index (CTDI) and its derivatives, dose length product (DLP), and effective dose. ${ }^{10}$ Volume computed tomography dose index $\left(\mathrm{CTDI}_{\mathrm{vol}}\right)$ is the most widely used indicator now. It is affected by the input scanning parameters such as tube voltage, tube current, rotation time, pitch, and beamwidth. ${ }^{11,12}$ However, it really only monitors scanner radiation output; it is independent of patient size, and

(C) 2021 Winda Kusuma Dewi, Choirul Anam, Eko Hidayanto, Arrum Nitasari, Geoff Dougherty. This is an open access article licensed under the Creative Commons Attribution-NonCommercial-NoDerivs License (http://creativecommons.org/licenses/by-nc-nd/4.0/). 
thus, it does not indicate the radiation received by the patient's body. It is well-known that an accurate metric of the patient dose is not only affected by the scanning parameters, but by the patient's size and attenuation. ${ }^{\mathbf{1 3}} \mathrm{A}$ more appropriate metric corresponding to the patient geometrical size is the size-specific dose estimate (SSDE), introduced by the American Association of Physicists in Medicine (AAPM) in Report No 204. ${ }^{\mathbf{1 4}}$

A specific geometrical size factor was used to normalize $\mathrm{CTDI}_{\mathrm{vol}}$ to obtain the SSDE value. The fundamental geometrical sizes are anterior-posterior (AP) and lateral (LAT) dimensions, and an advanced geometrical size is an effective diameter $\left(D_{\text {eff }}\right)$, which can be calculated from AP and LAT dimensions. An approximation to $\mathrm{D}_{\text {eff }}$ using AP or LAT is very helpful for the busy clinical center. This approximation is based on the relationship between AP and $\mathrm{D}_{\text {eff }}$, or LAT and $\mathrm{D}_{\text {eff }}$.

Unfortunately, the geometrical size given in AAPM Report No. 204 does not take into consideration any tissue attenuation and consequently, the dose calculation becomes less accurate. AAPM Report No. $220,{ }^{15}$ introduced a more robust size metric defined as the water-equivalent diameter $\left(D_{w}\right)$. Tissue attenuation could be evaluated from the average CT number value in the patient field of view (FoV) to enable variations in patient inhomogeneity.

Assessment of either $\mathrm{D}_{\text {eff }}$ or $\mathrm{D}_{\mathrm{w}}$ can be performed once the scanning procedure is completed, but it is time-consuming. Recently, new methods to automatically calculate $D_{\text {eff }}$ and $D_{w}$ have been reported. ${ }^{16,17} \mathrm{~A}$ comprehensive study of the relationships between $D_{\text {eff }}$ and $D_{w}$ and geometrical size is required to obtain an accurate patient dose. ${ }^{\mathbf{1 8 , 1 9}}$ AAPM No. 204 reported the correlations of $D_{\text {eff }}$ vs geometrical size in the abdominal region only. ${ }^{\mathbf{1 4}}$ The aim of the current work is to establish robustly patient size in terms of $D_{\text {eff }}$ and $D_{w}$ as a function of AP and LAT dimensions in order to predict accurate patient dose for thoracic, abdominal, and pelvic regions from CT examinations.

\section{Materials and Methods}

\section{CT Images}

Axial clinical images from thoracic, abdominal and pelvic examinations were retrospectively collected in the digital imaging and communications in medicine (DICOM) format from two hospitals. We selected 47 images from patients who underwent thoracic examinations. They were scanned using a Siemens Sensation CT scanner (64 slices) with scanning parameters of $120 \mathrm{kVp}$ tube voltage, $0.5 \mathrm{~s}$ rotation time, and 1.399 pitch. We used 79 abdominal images and 50 pelvic images scanned using a GE Optima CT580 with a tube voltage of 120 $\mathrm{kVp}$, rotation time of $0.8 \mathrm{~s}$, and 0.9375 pitch. Examples of images used in this study are shown in Figure 1. Patient ages were from 1 to 84 years old. Tube current modulation (TCM) was activated during all examinations to reduce the dose given.
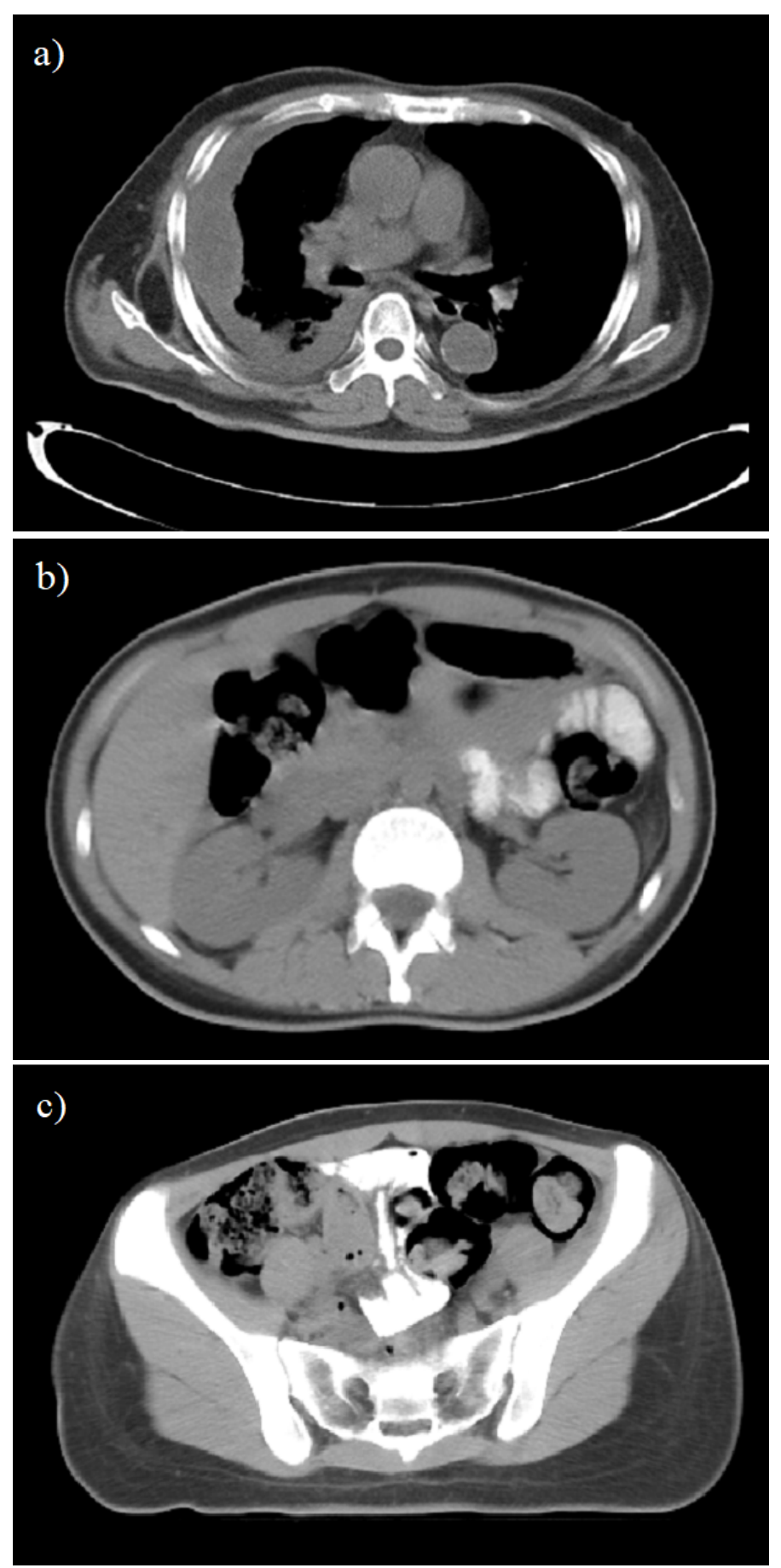

Figure 1. Examples of images used in the current study, (a) thoracic, (b) abdominal, and (c) pelvic regions. 


\section{Determination of AP, LAT, $D_{\text {eff, }} D_{w}$, and ellipticity ratio}

The AP, LAT, $D_{\text {eff }}$, and $D_{w}$ values were automatically measured from axial CT images using IndoseCT version 20b software. Automated segmentation comprised thresholding, object recognition by edge detection, labeling, and calculation of the object area. The largest area of the objects was defined as the patient's perimeter. ${ }^{19}$ The software provided the effective diameter value from three alternative options, namely "Area", "Center", and "Max". We chose the AP and LAT dimensions at the position that gave a maximum value ("Max" option), as shown in Figure 2. The square root of the product of AP and LAT dimensions gives the $\mathrm{D}_{\text {eff }}$ value. ${ }^{\mathbf{1 4}}$

$D_{\text {eff }}=\sqrt{A P \times L A T}$

Eq. 1

As reported in a previous study, ${ }^{17} \mathrm{D}_{\text {eff }}$ calculations using the patient cross-sectional area or the maximum value showed no significant difference. ${ }^{17}$ The calculation of $D_{w}$ utilized automated segmentation, ${ }^{\mathbf{1 6}}$ whose results were used to crop the initial image. The $D_{w}$ calculation referred to Equation 2:15

$D_{w}=2 \sqrt{\left[\frac{1}{1000} \overline{H U(x, y)_{R O I}}+1\right] \frac{A_{R O I}}{\pi}}$

Eq. 2

where $A_{R O I}$ represents the patient area after cropping and $H U(x, y)_{R O I}$ is the mean CT number inside the patient's region of interest (ROI). A previous study showed that the percentage difference between automatic and manual calculation was less than $0.5 \% .^{16}$

This current work also calculated the ellipticity ratio (r) for all three regions. The ellipticity ratio is calculated as the ratio of LAT to AP dimension. We reported the average, standard deviation, minimum and maximum values of ellipticity ratio in the three regions.

\section{Correlations of AP, LAT, $D_{\text {eff, }}$ and $D_{w}$}

AAPM Report No 204 provided curves of $D_{\text {eff }}$ as functions of AP, LAT, and AP + LAT to estimate the specific geometricalsize conversion factor in the abdominal region. $\mathrm{D}_{\text {eff }}$ and $\mathrm{AP}$, and $\mathrm{D}_{\text {eff }}$ and LAT were correlated with each other as second-order polynomial functions (Equation 3).

$y=a x^{2}+b x+c$

Eq. 3

$D_{\text {eff }}$ was correlated with AP+LAT as a linear function (Equation 4):

$y=a x+b$

Regression analysis and scatter data points were used to characterize the dependency of $\mathrm{D}_{\text {eff }}$ and $\mathrm{D}_{\mathrm{w}}$ on AP, LAT, and $\mathrm{AP}+\mathrm{LAT}$ dimensions. $\mathrm{R}$-squared $\left(\mathrm{R}^{2}\right)$ values were also provided in this study to assess the concurrence level of the correlation between $\mathrm{D}_{\text {eff }}$ and $\mathrm{D}_{\mathrm{w}}$ to the geometrical-size functions.
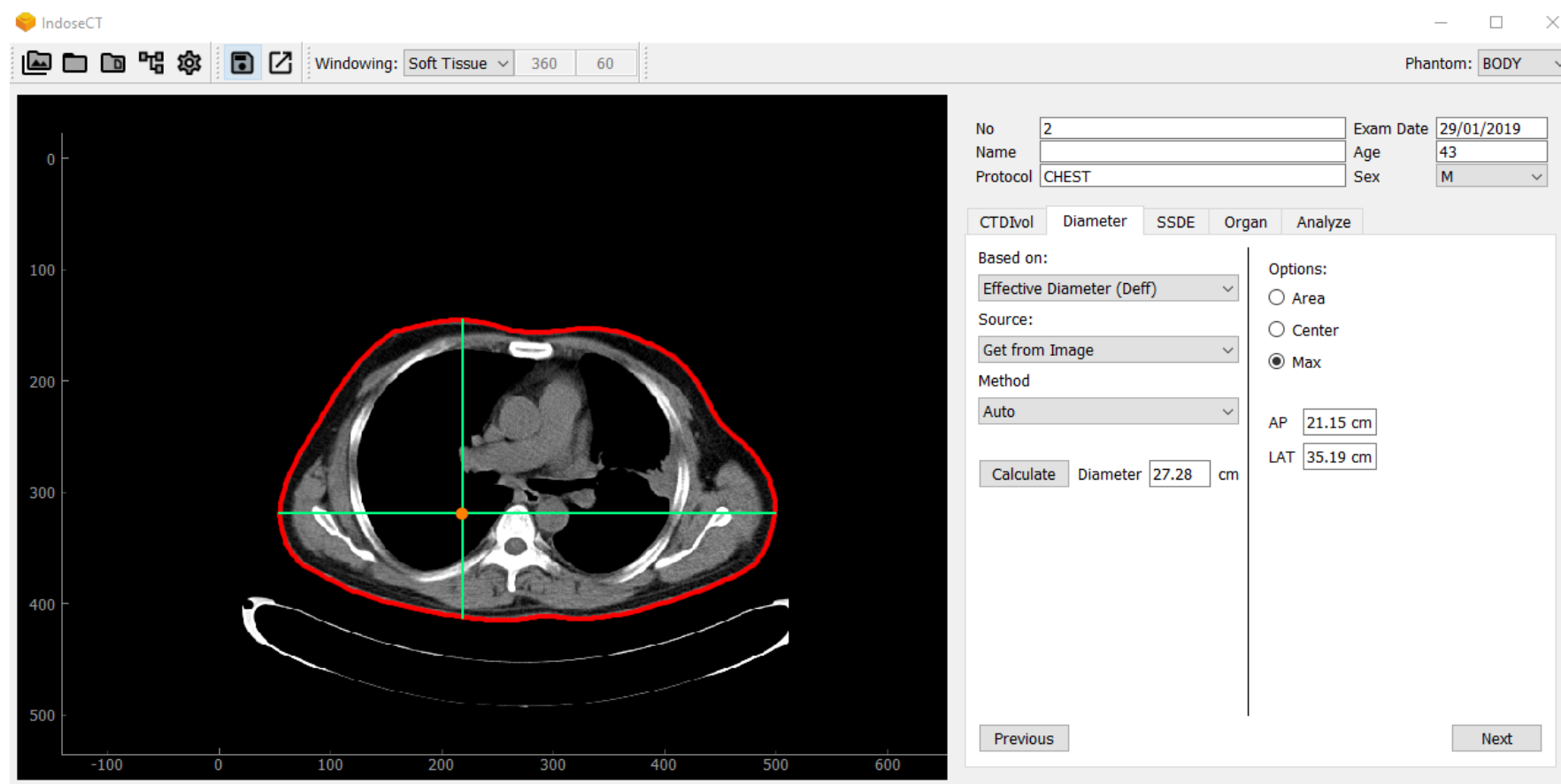

$\triangle$ Sort Images $\langle 24 / 33\rangle \quad 1 \quad$ Go to slice

Save Record to Database

Figure 2. IndoseCT $20 \mathrm{~b}$ offers automatic calculations of AP, LAT, and Deff calculation by three alternative options namely "Area", "Center", and "Max". We opted to use the "Max". The software also offers automatic $D_{w}$ calculation by choosing "The water-equivalent diameter". 


\section{Results}

\section{Thoracic region}

Figure 3 shows $D_{\text {eff }}$ and $D_{w}$ plotted against geometrical sizes (LAT, AP and LAT+AP) for the thoracic region. The best fitted lines for $\mathrm{D}_{\text {eff }}$ and $\mathrm{D}_{\mathrm{w}}$ in terms of LAT or AP are second-order polynomial fits. The coefficients are shown in each figure, together with the coefficients of determination, $\mathrm{R}^{2}$. The best fit lines for $D_{\text {eff }}$ and $D_{w}$ in terms of AP+LAT are first-order polynomials, and the corresponding coefficients and $\mathrm{R}^{2}$ values are given within each figure. Figure $\mathbf{3 g}$ shows that $D_{w}$ is linearly related to $\mathrm{D}_{\text {eff }}$ with a slope of 0.8447 , an intercept of 0.6733 , and $\mathrm{R}^{2}$ of 0.9474 . The average patient sizes are tabulated in Table 1. In the thoracic region, the average value of $D_{\text {eff }}$ is greater than $\mathrm{D}_{\mathrm{w}}$.
Table 1. Patient size obtained from the current study in the thoracic region.

\begin{tabular}{ccc}
\hline \hline Dimensions & Mean \pm Std. Dev $(\mathbf{c m})$ & Range $(\mathbf{c m})$ \\
\hline LAT & $30.39 \pm 4.42$ & $16.03-38.22$ \\
AP & $18.87 \pm 2.89$ & $11.25-24.40$ \\
AP + LAT & $49.26 \pm 7.13$ & $27.28-62.62$ \\
D $_{\text {eff }}$ & $24.08 \pm 3.53$ & $13.54-30.97$ \\
$\mathrm{D}_{\mathrm{w}}$ & $21.01 \pm 3.14$ & $12.21-26.13$ \\
\hline
\end{tabular}
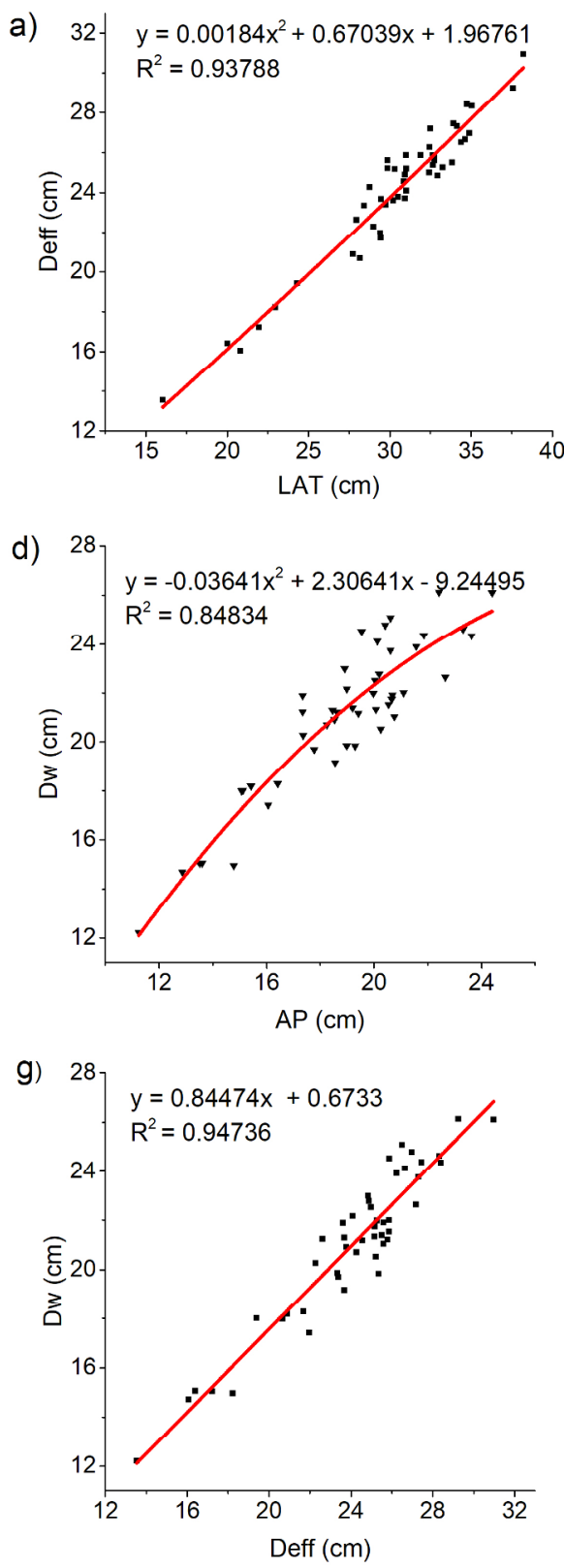
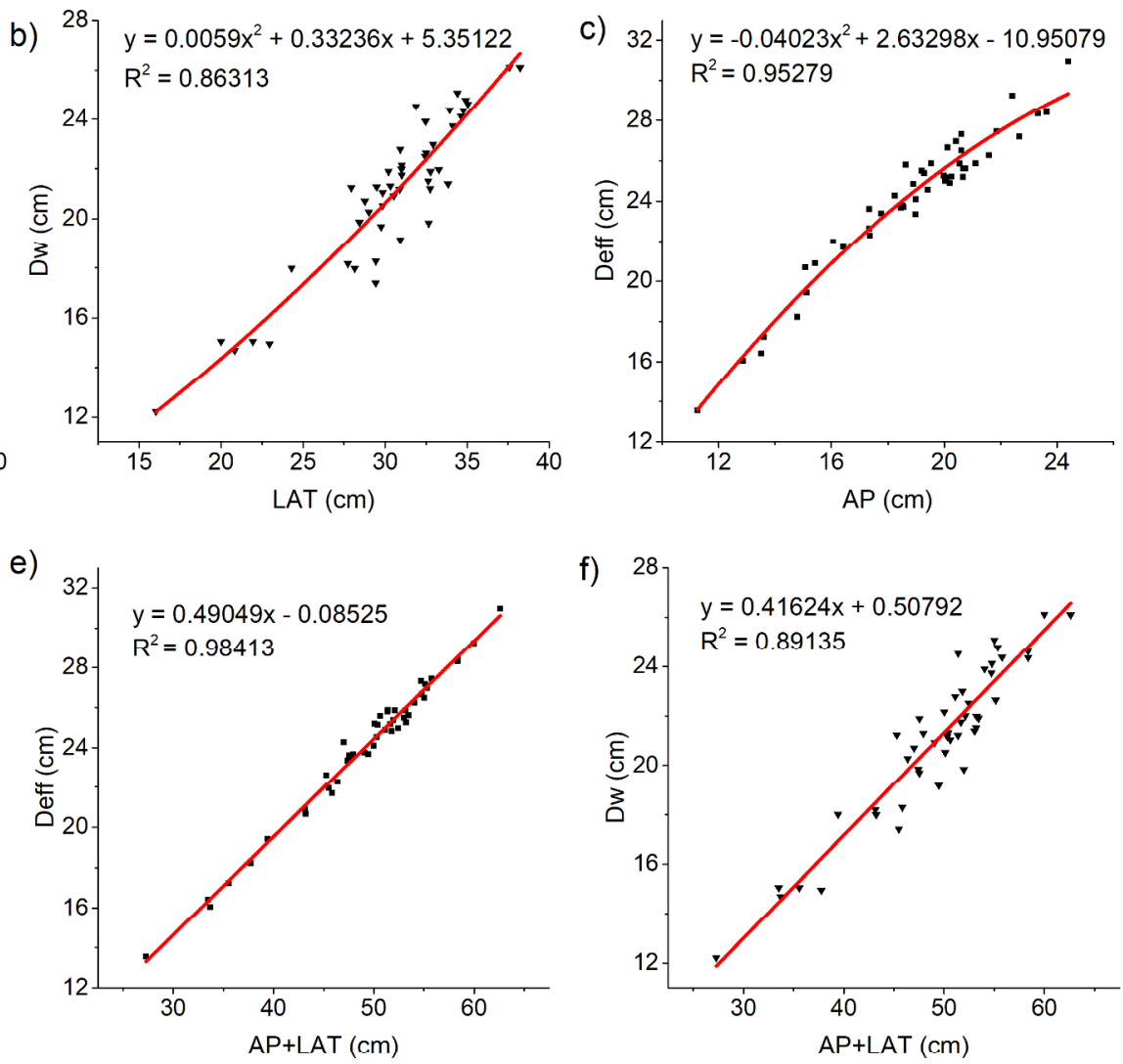

Figure 3. $D_{\text {eff }}$ and $D_{w}$ values as functions of the geometrical-size for the thoracic region, (a) $D_{\text {eff }}$ vs LAT, (b) $D_{w}$ vs LAT, (c) $D_{\text {eff }}$ vs AP, (d) $D_{w}$ vs AP, (e) $D_{\text {eff }}$ vs AP+LAT, (f) $D_{w}$ vs AP+LAT, and (g) $D_{w}$ vs $D_{\text {eff. }}$ 


\section{Abdominal region}

The correlations between $\mathrm{D}_{\text {eff }}$ and $\mathrm{D}_{\mathrm{w}}$ as functions of geometrical diameters in the abdominal region are shown in Figure 4. The best-fitted lines for $D_{\text {eff }}$ and $D_{w}$ in terms of LAT or AP are second-order polynomial fits, and the coefficients and $\mathrm{R}^{2}$ values are shown in each figure. The lines are curved in the opposite directions to those for the thoracic regions. The best fit lines for $\mathrm{D}_{\text {eff }}$ and $\mathrm{D}_{\mathrm{w}}$ in terms of AP+LAT are first-order polynomials, and the corresponding coefficients and $\mathrm{R}^{2}$ values are given within each figure. Figure $\mathbf{4 g}$ shows that $\mathrm{D}_{\mathrm{w}}$ is linearly related to $\mathrm{D}_{\mathrm{eff}}$ with a slope of 0.9599 , an intercept of 0.6831 , and $\mathrm{R}^{2}$ of 0.9908 . Table 2 shows the range of patient dimensions for the abdominal region. The average values of $D_{w}$ and $D_{\text {eff }}$ are similar.
Table 2. Patient size obtained from the current study in the abdominal region.

\begin{tabular}{ccc}
\hline \hline Dimensions & Mean \pm Std. Dev $(\mathbf{c m})$ & Range $(\mathbf{c m})$ \\
\hline LAT & $29.71 \pm 3.48$ & $22.53-39.94$ \\
AP & $21.47 \pm 3.43$ & $14.32-29.2$ \\
AP + LAT & $51.18 \pm 6.76$ & $37.4-69.14$ \\
D $_{\text {eff }}$ & $25.97 \pm 3.55$ & $18.67-35.90$ \\
D $_{\mathrm{w}}$ & $25.61 \pm 3.42$ & $18.70-35.09$ \\
\hline \hline
\end{tabular}

a)

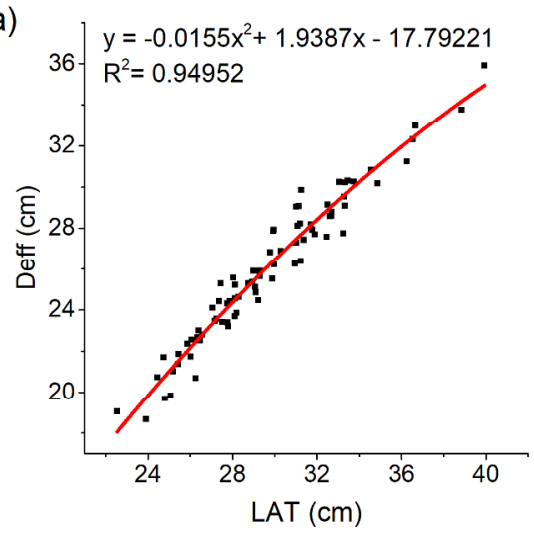

d) $36-y=0.00965 x^{2}+0.55102 x+9.21494$

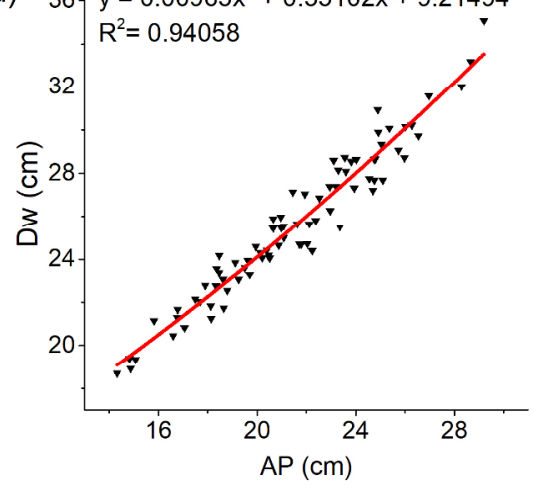

g)

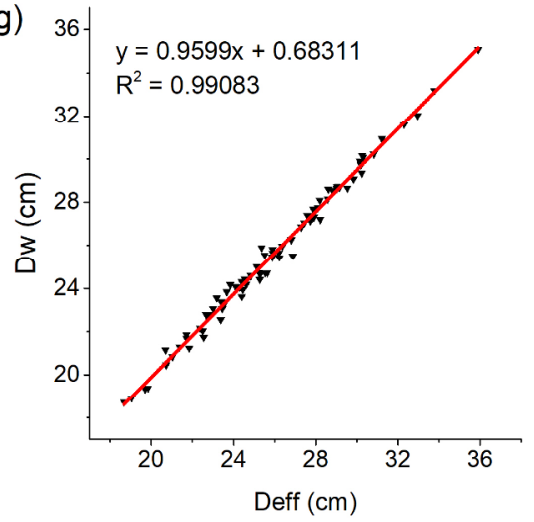

b)

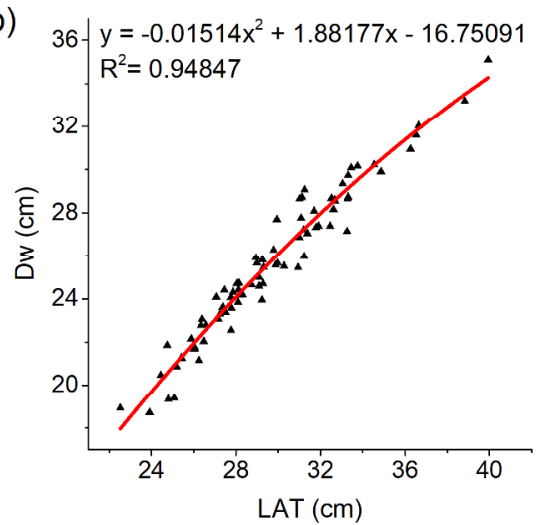

e)

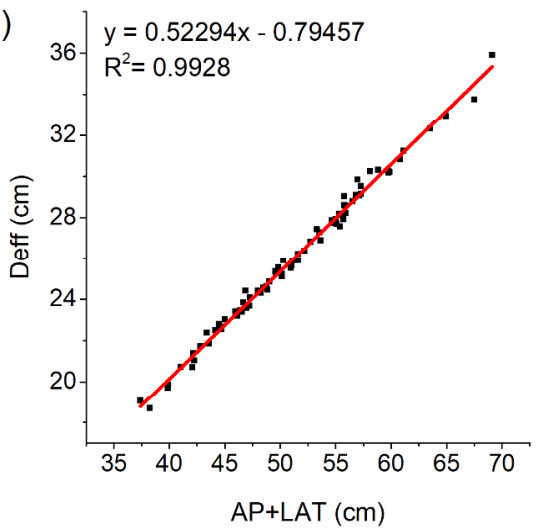

c)
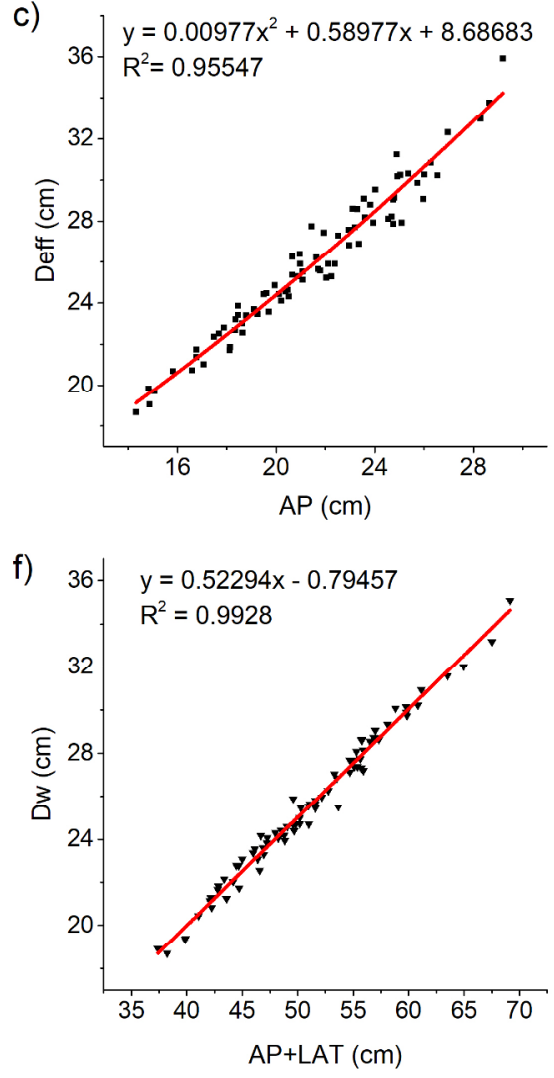

Figure 4. $D_{\text {eff }}$ and $D_{w}$ values as functions of geometrical-size for abdomen region, (a) $D_{\text {eff }} v s$ LAT, (b) $D_{w}$ vs LAT, (c) $D_{\text {eff }}$ vs AP, (d) $D_{w}$ vs AP,

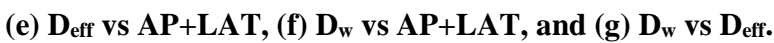




\section{Pelvic region}

The correlations between $\mathrm{D}_{\text {eff }}$ and $\mathrm{D}_{\mathrm{w}}$ as functions of geometrical diameters in the abdominal region are shown in Figure 5. All graphs are best fitted with downward curving second-order polynomial functions. Figure $\mathbf{5 g}$ shows that $D_{w}$ is linearly related to $D_{\text {eff }}$ with a slope of 0.9205 , an intercept of 2.1814 , and $\mathrm{R}^{2}$ of 0.9795 . Table 3 shows the range of patient dimensions for the pelvic region. The average values of $D_{w}$ and $D_{\text {eff }}$ are also similar in the pelvic region.
Table 3. Patient size obtained from the current study in the pelvic region.

\begin{tabular}{ccc}
\hline \hline Dimensions & Mean \pm Std. Dev $(\mathbf{c m})$ & Range $(\mathbf{c m})$ \\
\hline LAT & $32.47 \pm 3.43$ & $26.06-38.69$ \\
AP & $19.48 \pm 2.54$ & $13.19-24.52$ \\
AP + LAT & $51.95 \pm 5.79$ & $39.50-62.93$ \\
$\mathrm{D}_{\text {eff }}$ & $25.96 \pm 2.78$ & $19.08-30.97$ \\
$\mathrm{D}_{\mathrm{w}}$ & $26.08 \pm 2.58$ & $19.11-30.93$ \\
\hline \hline
\end{tabular}
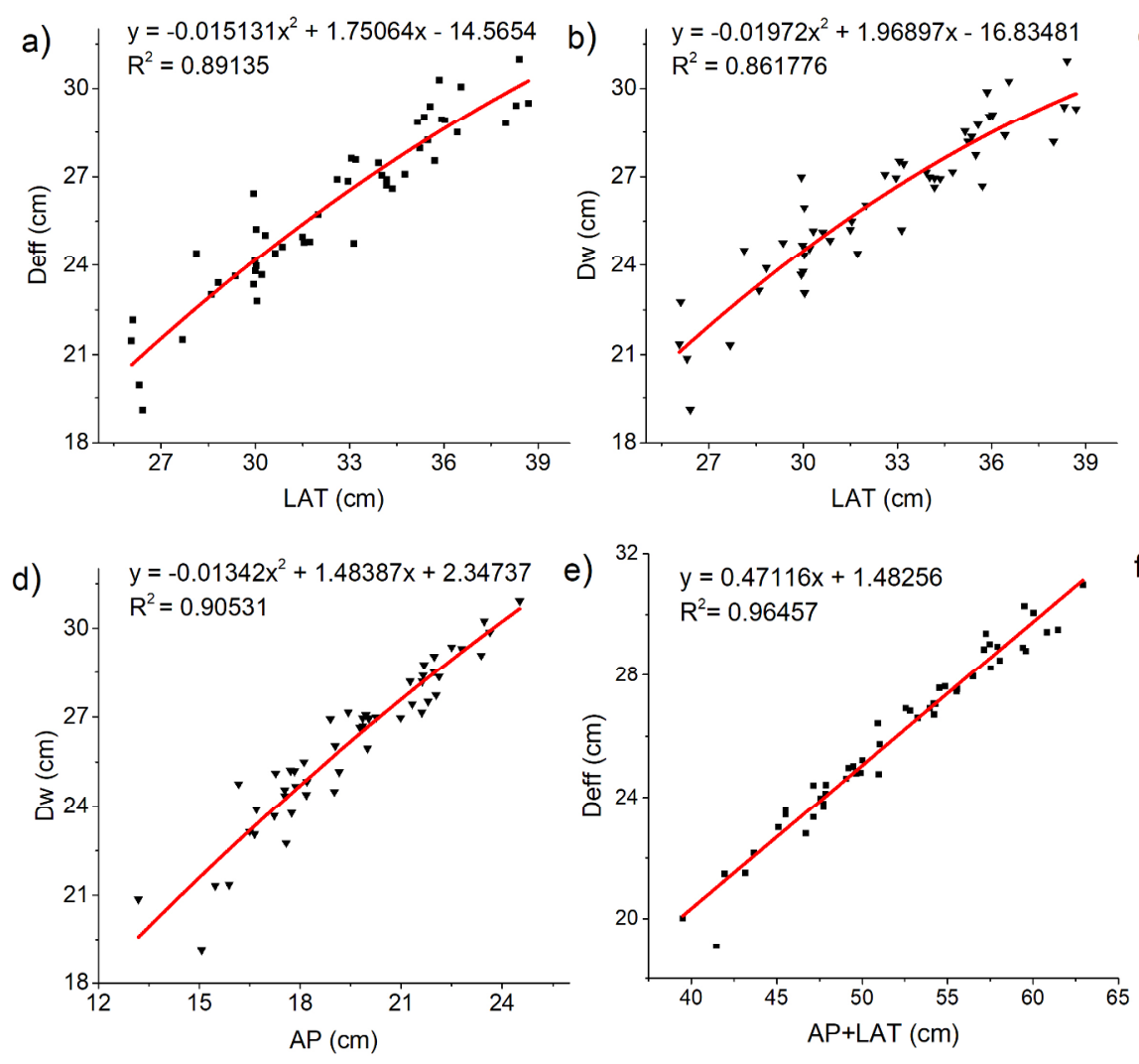

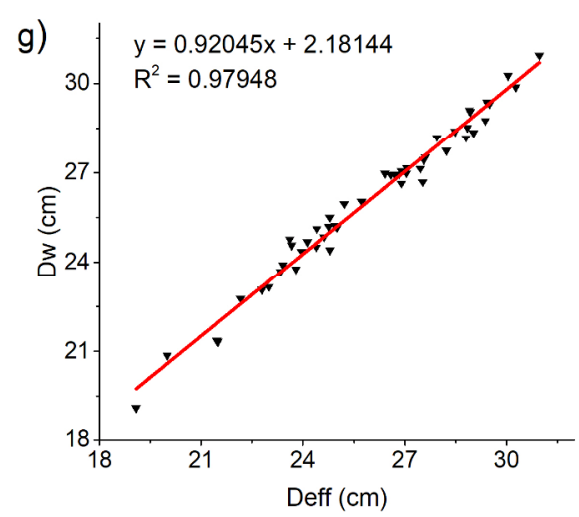

Figure 5. $D_{\text {eff }}$ and $D_{w}$ values as functions of geometrical-size for pelvic region, (a) $D_{\text {eff }}$ vs LAT, (b) $D_{w}$ vs LAT, (c) Deff vs AP, (d) D $D_{w}$ vs AP, (e)

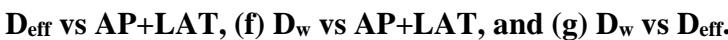


Table 4. Calculation of elliptical ratio $(r=L A T / A P)$ obtained from our study.

\begin{tabular}{ccc}
\hline \hline Body region & Mean \pm Std. Dev & Range \\
\hline Thorax & $1.62 \pm 0.11$ & $1.42-1.87$ \\
Abdomen & $1.40 \pm 0.11$ & $1.19-1.69$ \\
Pelvic & $1.68 \pm 0.11$ & $1.43-1.99$ \\
\hline \hline
\end{tabular}

\section{Ellipticity ratio}

The ellipticity ratios (LAT/AP) from the three regions i.e. thorax, abdomen, and pelvis, are tabulated in Table 4. The highest ellipticity ratio is found in the pelvic region $(r=$ $1.68 \pm 0.11)$, followed by the thoracic region $(r=1.62 \pm 0.11)$, and the smallest value is found in the abdominal region $(1.40 \pm 0.11)$. The ellipticity ratio obtained from this current work is more than unity which means the LAT dimension is longer than AP dimension. It is consistent with the images used as we have shown in Figure 1.

\section{Discussions}

The SSDE is the most robust metric to quantify the radiation dose received by a patient from a CT scanner. It is obtained by normalizing the CT scanner output $\left(\mathrm{CTDI}_{\mathrm{vol}}\right)$ with a sizeconversion factor $(f)$. The size-conversion factor was derived from four independent cohort investigators. Two of the investigators derived it using Monte Carlo-based measurement, whereas the others employed physical phantoms. ${ }^{14}$ The utilization of the size-conversion factor was based on the geometrical diameter, which in this case refers to the effective diameter $\left(\mathrm{D}_{\text {eff }}\right)$. The $\mathrm{D}_{\text {eff }}$ value was calculated as the square root of the product of the AP and LAT dimensions. Usually, AP and LAT dimensions are measured manually or automatically from CT radiographs or axial CT images. ${ }^{\mathbf{2 0 - 2 2}}$

A metric that incorporates both geometrical size and tissue composition is the water-equivalent diameter $\left(D_{w}\right)$. The calculation of SSDE based on $\mathrm{D}_{w}$ can generally be done automatically. Dose monitoring systems are available and used in many radiology centers, and many of them automatically calculate SSDE. Some of them rely on patient dimensions calculated from CT radiographs, but some can calculate water equivalent diameter from axial images. ${ }^{\text {23-25 }}$ The $\mathrm{D}_{\text {eff }}$ for chest examination can be corrected for the presence of lung tissue to give a more accurate estimation of SSDE. ${ }^{\mathbf{2 6}}$

Approximating $\mathrm{D}_{\text {eff }}$ using only one dimension, AP or LAT, would be very helpful in the clinical environment so that it could be estimated from the CT radiograph which is usually scanned in one direction. It can be obtained in this way, if the relationships between $\mathrm{AP}$ and $\mathrm{D}_{\text {eff }}$, or LAT and $\mathrm{D}_{\text {eff }}$, are known. AAPM Report No 204 provided these relationships, but only for the abdominal region. The current study provides the relationships for three regions, i.e. thorax, abdomen, and pelvis, but not for the head.

The relationships between $\mathrm{D}_{\text {eff }}$ and LAT, AP, as well as $\mathrm{AP}+\mathrm{LAT}$ dimensions for the thorax region, are shown in Figure 3a, Figure 3c, and Figure 3e, respectively. $D_{\text {eff }}$ vs LAT dimension generates an upward curvature, $D_{\text {eff }}$ vs AP generates a downward curvature, and $\mathrm{D}_{\text {eff }}$ and $\mathrm{AP}+\mathrm{LAT}$ generate a linear correlation. The three curves all show strong correlations.

We also established the relationships between $D_{w}$ and AP and LAT dimensions, which make it easier to predict dose more accurately. The relationships between $\mathrm{D}_{\mathrm{w}}$ and LAT, AP, and $\mathrm{AP}+\mathrm{LAT}$ for the thorax region are shown in Figure 3b, Figure 3d, and Figure 3f. In the thoracic region, $D_{\text {eff }}$ is greater than $D_{w}$, because the lung mostly consists of air having very much lower pixel values than water.

For the abdominal region, the relationship of $D_{\text {eff }}$ and $D_{w}$ as functions of LAT, AP, and AP+LAT are shown in Figure 4. Our results are different from those given in AAPM Report No 204. In the latter report, the curve of $D_{\text {eff }}$ vs LAT had a slightly upward curvature, while our study finds a downward curvature. Similarly, for the $\mathrm{D}_{\text {eff }}$ vs AP curve, the AAPM reported slightly downward curvature, while our study finds a slightly upward curve. The data used by AAPM was obtained from a mathematical pediatric phantom, a water-equivalent cylindrical phantom, and CT examinations of pediatric patients. ${ }^{27-29}$ The geometric size on the AAPM curves represented a wide range of diameters (from LAT $=12.7 \mathrm{~cm}$ and $\mathrm{AP}=9.8 \mathrm{~cm}$ to $\mathrm{LAT}=44$ $\mathrm{cm}$ and $\mathrm{AP}=36 \mathrm{~cm}$ ). Our study used patients with a more limited range of sizes (from LAT $=22.53 \mathrm{~cm}$ and $\mathrm{AP}=14.32$ $\mathrm{cm}$ to $\mathrm{LAT}=39.94 \mathrm{~cm}$ and $\mathrm{AP}=29.20 \mathrm{~cm})$. We believe the slightly different trendlines are due to the different ranges of data. In addition, Burton el al. ${ }^{\mathbf{1 9}}$ reported the linear correlations of $D_{\text {eff }}$ vs LAT and $D_{\text {eff }}$ vs AP in the abdomen region, which confirmed that the trendlines are dependent on the data used. We found that the $D_{\text {eff }}$ value is similar to $D_{w}$ in the abdominal region. This is because the composition of the abdomen is mostly soft tissue with CT numbers similar to water.

The relationships of $D_{\text {eff }}$ and $D_{w}$ as functions of the geometrical sizes for the pelvic regions are shown in Figure 5. All the curves have downward curvature. In the pelvic area, the average value of $D_{w}$ is similar to $D_{\text {eff. Previously, we expected }}$ that the average value of $D_{w}$ will be higher than $D_{\text {eff }}$ because the composition of the pelvis is soft tissue and dense bone with CT numbers more than $+1000 \mathrm{HU}$. However, the results of the current study revealed that the $D_{w}$ is only $0.14 \mathrm{~cm}$ higher than the $\mathrm{D}_{\text {eff. }}$ On the other hand, $\mathrm{D}_{\mathrm{w}}$ is similar to $\mathrm{D}_{\text {eff. }}$ This may be due to the existence of fat with the -150 to $-50 \mathrm{HU}$ range. ${ }^{30}$ Combination of bone and fat may lead the $\mathrm{D}_{\mathrm{w}}$ is similar with the $D_{\text {eff. }}$ 
Table 5. $R^{2}$ value and best fit parameters between $D_{\text {eff }}$ and AP, $D_{\text {eff }}$ and LAT, $D_{\text {eff }}$ and (AP+LAT), $D_{w}$ and AP, $D_{w}$ and LAT, $D_{w}$ and (AP+LAT), and $D_{w}$ vs $D_{\text {eff }}$ for the thoracic region.

\begin{tabular}{|c|c|c|c|c|c|c|c|}
\hline & Deff $_{\text {ef }}$ LAT & $\mathbf{D}_{\mathrm{w}}-\mathbf{L A T}$ & $\mathbf{D}_{\text {eff }}-\mathbf{A P}$ & $\mathbf{D}_{\mathbf{w}}-\mathbf{A P}$ & $D_{\text {eff }}-(\mathbf{A P}+\mathbf{L A T})$ & $D_{w}-(A P+L A T)$ & $D_{w}-D_{\text {eff }}$ \\
\hline $\mathrm{R}^{2}$ value & 0.9379 & 0.8631 & 0.9528 & 0.8483 & 0.9841 & 0.8913 & 0.9474 \\
\hline a value & 0.0018 & 0.0059 & -0.0402 & -0.0364 & 0.4905 & 0.4162 & 0.8447 \\
\hline $\mathrm{b}$ value & 0.6704 & 0.3324 & 2.6330 & 2.3064 & 0.0852 & 0.5079 & 0.6733 \\
\hline c value & 1.9676 & 5.3512 & -10.9508 & -9.2449 & - & - & - \\
\hline
\end{tabular}

Table 6. $R^{2}$ value and fit parameters between $D_{\text {eff }}$ and AP, $D_{\text {eff }}$ and LAT, $D_{\text {eff }}$ and (AP+LAT), $D_{w}$ and AP, $D_{w}$ and LAT, D $D_{w}$ and (AP+LAT), and $D_{w}$ vs $D_{\text {eff }}$ for the abdominal region.

\begin{tabular}{cccccccc}
\hline \hline & $\mathbf{D}_{\text {eff }}-\mathbf{L A T}$ & $\mathbf{D}_{\mathrm{w}}-\mathbf{L A T}$ & $\mathbf{D}_{\text {eff }}-\mathbf{A P}$ & $\mathbf{D}_{\mathrm{w}}-\mathbf{A P}$ & $\mathbf{D}_{\text {eff }}-(\mathbf{A P}+\mathbf{L A T})$ & $\mathbf{D}_{\mathrm{w}}-(\mathbf{A P + L A T})$ & $\mathbf{D}_{\mathrm{w}}-\mathbf{D}_{\text {eff }}$ \\
\hline $\mathrm{R}^{2}$ value & 0.9495 & 0.9485 & 0.9555 & 0.9406 & 0.9928 & 0.9944 & 0.9908 \\
a value & -0.0155 & -0.0151 & 0.0098 & 0.0096 & 0.5229 & 0.5021 & -0.0890 \\
$\mathrm{~b}$ value & 1.9387 & 1.8818 & 0.5898 & 0.5510 & -0.7946 & - & - \\
$\mathrm{c}$ value & -17.7922 & -16.7509 & 8.6868 & 9.2149 & - & - \\
\hline \hline
\end{tabular}

Table 7. $R^{2}$ value and fit parameters between $D_{\text {eff }}$ and AP, $D_{\text {eff }}$ and LAT, $D_{\text {eff }}$ and $(A P+L A T), D_{w}$ and AP, $D_{w}$ and LAT, $D_{w}$ and $(A P+L A T)$, and $D_{w} v s$ Deff for the pelvic region.

\begin{tabular}{|c|c|c|c|c|c|c|c|}
\hline & $D_{\text {eff }}-\mathbf{L A T}$ & $\mathbf{D}_{\mathrm{w}}-\mathrm{LAT}$ & $\mathbf{D}_{\text {eff }}-\mathbf{A P}$ & $\mathbf{D}_{w}-\mathbf{A P}$ & $D_{\text {eff }}-(A P+L A T)$ & $D_{w}-(A P+L A T)$ & $D_{w}-D_{\text {eff }}$ \\
\hline $\mathrm{R}^{2}$ value & 0.8914 & 0.8618 & 0.9290 & 0.9053 & 0.9690 & 0.9401 & 0.9795 \\
\hline a value & -0.0151 & -0.0197 & -0.0143 & -0.0134 & -0.0052 & -0.0061 & 0.9204 \\
\hline $\mathrm{b}$ value & 1.7506 & 1.9690 & 1.6040 & 1.4839 & 1.0069 & 1.0630 & 2.1814 \\
\hline $\mathrm{c}$ value & -14.5654 & -16.8348 & 0.2306 & 2.3474 & - & - & - \\
\hline
\end{tabular}

The fit parameters obtained from the current work are summarized in Tables 5-7. It shows that $R^{2}$ values for the relationships between $\mathrm{D}_{\text {eff }}$ and geometrical sizes are greater than 0.9 , and greater than 0.8 for the relationships between $\mathrm{D}_{\mathrm{w}}$ and geometrical sizes. This confirms that an accurate estimation of $\mathrm{D}_{\text {eff }}$, and even $\mathrm{D}_{\mathrm{w}}$, can be obtained by using only one dimension, either AP or LAT. However, estimating $\mathrm{D}_{\text {eff }}$ and $\mathrm{D}_{\mathrm{w}}$ using the two dimensions, AP and LAT, is more accurate if both are available. Although $\mathrm{D}_{\mathrm{w}}$ can be estimated with the relationships obtained from the current study, it is suggested that its value should be obtained directly from the image using Equation 2. However, calculating the patient area and the mean HU value in the patient image is not easy in a clinical setting.

This study also shows a strong $\left(\mathrm{R}^{2}>0.9\right)$ correlation of $\mathrm{D}_{\mathrm{w}}$ with $D_{\text {eff. }}$ We mentioned that $D_{w}$ is the more robust indicator in estimating the dose received because it takes into account the tissue composition. ${ }^{31} D_{w}$ can be easily estimated from $D_{\text {eff }}$ because of the linear relationship built between the two indicators.

In this study, we calculated the elliptical ratios for the three regions. Our elliptical ratios are consistent with Burton et al. ${ }^{19}$, who reported that the elliptical ratios for the thorax and abdomen were $1.51 \pm 0.21$ and $1.38 \pm 0.20$, respectively. Our elliptical ratio for the pelvic region was $1.68 \pm 0.11$. Burton et al. ${ }^{19}$ did not report the elliptical ratio in this region but reported $1.48 \pm 0.22$ for abdomen-pelvis.
This study has several limitations. It is a retrospective study based on limited numbers (176) of patient images from the thorax, abdomen, and pelvic regions of local (Indonesian) patients. Further investigations are required for a larger range of LAT and AP dimensions.

\section{Conclusion}

The relationships between the constructed diameters, the effective diameter $\left(D_{\text {eff }}\right)$ and water-equivalent diameter $\left(D_{w}\right)$, and the basic geometric diameters, lateral (LAT), anteriorposterior (AP), and AP+LAT dimensions, were studied using 47 thoracic images, 79 abdominal images, and 50 pelvic images. The $R^{2}$ values for the relationships between $D_{\text {eff }}$ and the geometrical sizes were greater than 0.9 , and were greater than 0.8 for the relationships between $\mathrm{D}_{\mathrm{w}}$ and the geometrical sizes. We found that an accurate estimation of $D_{\text {eff }}$ and $D_{w}$ can be obtained by using only one dimension, either AP or LAT. We also found that in the thoracic region the average value of $D_{\text {eff }}$ is higher than $\mathrm{D}_{\mathrm{w}}$, in the abdominal and pelvic regions the average values of $D_{\text {eff }}$ and $D_{w}$ are similar. Since $D_{w}$ includes tissue attenuation, it is the more accurate parameter for CT dose estimation. Fortunately, $\mathrm{D}_{\mathrm{w}}$ has strong linear relationships with the other dimensions, and can readily be estimated from them. 


\section{Acknowledgement}

This work was funded by the Riset Publikasi International Bereputasi Tinggi (RPIBT), Diponegoro University (No. 329116/UN7.6.1/PP/2021).

\section{Conflict of Interest}

Dr. Choirul Anam is one of the IndoseCT developers. However, the IndoseCT is not commercially available and it can be made available on request for research purposes. The rest of the authors have no conflicts of interest to disclose.

\section{References}

1. Ginat DT, Gupta R. Advances in computed tomography imaging technology. Annu Rev Biomed Eng. 2014;16:431-53. https://doi.org/10.1146/annurev-bioeng-121813-113601

2. Tabari A, Lo Gullo R, Murugan V, Otrakji A, Digumarthy S, Kalra M. Recent advances in computed tomographic technology. J Thorac Imaging. 2017;32(2):89-100. https://doi.org/10.1097/RTI.0000000000000258

3. Romans LE. Computed tomography for technologists: A comprehensive text, second edition. Computed Tomography for Technologists: A Comprehensive Text. 2011.

4. Anam C, Haryanto F, Widita R, Arif I, Dougherty G, McLean D. Volume computed tomography dose index (CTDIvol) and sizespecific dose estimate (SSDE) for tube current modulation (TCM) in CT scanning. Int J Radiat Res. 2018;16(3):289-97.

5. Khan A, Khosa F, Nasir K, Yassin A, Clouse ME. Comparison of radiation dose and image quality: 320-MDCT versus 64-MDCT coronary angiography. Am J Roentgenol. 2011;197(1):163-8. https://doi.org/10.2214/AJR.10.5250

6. NHS England. Diagnostic imaging dataset annual statistical. NHS Engl Internet.. 2020;1-29. Available from: https://www.england.nhs.uk/statistics/wp-content/uploads/sites/2/2020/10/Annual-Statistical-Release-2019-20-PDF-1.4MB.pdf

7. Juliusson G, Thorvaldsdottir B, Kristjansson JM, Hannesson P. Diagnostic imaging trends in the emergency department: an extensive single-center experience. Acta Radiol Open. 2019;8(7):205846011986040. https://doi.org/10.1177/2058460119860404

8. Pola A, Corbella D, Righini A, et al. Computed tomography use in a large italian region: Trend analysis 2004-2014 of emergency and outpatient ct examinations in children and adults. Eur Radiol. 2018;28(6):2308-18. https://doi.org/10.1007/s00330-017-5225-x

9. Smith-Bindman R, Wang Y, Chu P, et al. International variation in radiation dose for computed tomography examinations: Prospective cohort study. BMJ. 2019;364:k4931. https://doi.org/10.1136/bmj.k4931

10. Bauhs JA, Vrieze TJ, Primak AN, Bruesewitz MR, McCollough CH. CT dosimetry: comparison of measurement techniques and devices. Radiographics. 2008;28(1):245-53. https://doi.org/10.1148/rg.281075024

11. Huda W, Mettler FA. Volume CT dose index and dose-length product displayed during CT: What good are they? Radiology. 2011;258(1):236-42. https://doi.org/10.1148/radiol.10100297

12. Anam C, Budi WS, Adi K, et al. Assessment of patient dose and noise level of clinical CT images: automated measurements. J Radiol Prot. 2019;39(3):783-93. https://doi.org/10.1088/1361-6498/ab23cc

13. McCollough CH, Leng S, Yu L, Cody DD, Boone JM, McNitt-Gray MF. CT dose index and patient dose : They are not the same thing. Radiology. 2011;259(2):311-6. https://doi.org/10.1148/radiol.11101800

14. The Report of AAPM Task Group 204. Size-specific dose estimates (SSDE) in paediatric and adult body CT examinations. 2011. https://www.aapm.org/pubs/reports/RPT_204.pdf.

15. The Report of AAPM Task Group 220. Use of water equivalent diameter for calculating patient size and size-specific dose estimates (SSDE) in CT. 2014. https://www.aapm.org/pubs/reports/RPT_220.pdf.

16. Anam C, Haryanto F, Widita R, Arif I, Dougherty G. Automated calculation of water-equivalent diameter (DW) based on AAPM task group 220. J Appl Clin Med Phys. 2016;17(4):320-33. https://doi.org/10.1120/jacmp.v17i4.6171

17. Anam C, Haryanto F, Widita R, Arif I, Dougherty G. The evaluation of the effective diameter (Deff) calculation and its impact on the size-specific dose estimate (SSDE). Atom Indonesia. 2017;43(1):55-60. https://doi.org/10.17146/aij.2017.617

18. Gabusi M, Riccardi L, Aliberti C, Vio S, Paiusco M. Radiation dose in chest CT: Assessment of size-specific dose estimates based on water-equivalent correction. Phys Med. 2016;32(2):393-7. https://doi.org/10.1016/j.ejmp.2015.12.008

19. Burton CS, Szczykutowicz TP. Evaluation of AAPM reports 204 and 220: Estimation of effective diameter, water-equivalent diameter, and ellipticity ratios for chest, abdomen, pelvis, and head CT scans. J Appl Clin Med Phys. 2018;19(1):228-38. https://doi.org/10.1002/acm2.12223

20. Anam C, Haryanto F, Widita R, Arif I. Automated estimation of patient's size from 3D image of patient for size specific dose estimates (SSDE). Adv Sci Eng Med. 2015;7(10):892-6. https://doi.org/10.1166/asem.2015.1780

21. Brady SL, Kaufman RA. Investigation of American Association of Physicists in medicine report 204 size-specific dose estimates for pediatric CT implementation. Radiology. 2012;265(3):832-40. https://doi.org/10.1148/radiol.12120131 
22. Pourjabbar S, Singh S, Padole A, Saini A, Blake MA, Kalra M. Size-specific dose estimates: localizer or transverse abdominal computed tomography images? World J Radiol. 2014;6(5):210-7. https://doi.org/10.4329/wjr.v6.i5.210

23. Tsalafoutas IA, Kharita MH, Al-Naemi H, Kalra MK. Radiation dose monitoring in computed tomography: Status, options and limitations. Phys Med. 2020;79:1-15. https://doi.org/10.1016/j.ejmp.2020.08.020

24. Juszczyk J, Badura P, Czajkowska J, et al. Automated size-specific dose estimates using deep learning image processing. Med Image Anal. 2021;68:101898. https://doi.org/10.1016/j.media.2020.101898

25. Anam C, Fujibuchi T, Toyoda T, et al. A simple method for calibrating pixel values of the CT localizer radiograph for calculating water-equivalent diameter and size-specific dose estimate. Radiat Prot Dosim. 2018;179:158-68. https://doi.org/10.1093/rpd/ncx241

26. Mihailidis D, Tsapaki V, Tomara P. A simple manual method to estimate water-equivalent diameter for calculating size-specific dose estimate in chest computed tomography. Br J Radiol. 2020;93:20200473. https://doi.org/10.1259/bjr.20200473

27. Kleinman PL, Strauss KJ, Zurakowski D, Buckley KS, Taylor GA. Patient size measured on CT images as a function of age at a tertiary care children's hospital. Am J Roentgenol. 2010;194(6):1611-9. https://doi.org/10.2214/AJR.09.3771

28. Boone JM, Cooper VN, Nemzek WR, McGahan JP, Seibert JA. Monte Carlo assessment of computed tomography dose to tissue adjacent to the scanned volume. Med Phys. 2000;27(10):2393-407. https://doi.org/10.1118/1.1312809

29. ICRU. Patient dosimetry for X rays used in medical imaging. J ICRU. 2005;5(2):iv-vi. https://doi.org/10.1093/jicru_ndi018

30. Kim S, Lee GH, Lee S, Park SH, Pyo HB, Cho JS. Body fat measurement in computed tomography image. Biomed Sci Instrum. 1999;35:303-8.

31. Anam C, Arif I, Haryanto F, et al. A simplified method for the water-equivalent diameter calculation to estimate patient dose in CT examinations. Radiat Prot Dosim. 2019;185(1):42-9. https://doi.org/10.1093/rpd/ncy214 